\title{
Polymorphism and Association of DMA Gene with Total IgY Concentration and ND Antibody Titer in IPB-D2 Chicken Line
}

\author{
D. Lestari ${ }^{a}$, S. Murtini ${ }^{b}$, N. Ulupi ${ }^{a}$, \& C. Sumantri ${ }^{a, *}$ \\ aDepartment of Animal Production and Technology, Faculty of Animal Science, IPB University \\ ${ }^{b}$ Department of Animal Disease and Veterinary Public Health, Faculty of Veterinary Medicine, IPB University \\ Jalan Agatis, Kampus IPB Dramaga Bogor 16680, Indonesia \\ *Corresponding author: csumantri12@gmail.com \\ (Received 07-01-2021; Revised 08-04-2021; Accepted 13-04-2021)
}

\begin{abstract}
The DMA (DM $\alpha$ chain) gene, a member of non-classical MHC class II plays an important role in the process of presenting antigen peptides by producing DM protein. This study aimed to identify the polymorphism of DMA gene and their associations with disease resistance traits such as total IgY concentration and ND antibody titers in IPB-D2 chicken line. The total sample used was 101 chickens consisted of 81 IPB-D2 G0 chickens (53 female and 28 male) and 20 SENSI-1 chickens (15 female and 5 male). Blood samples were collected at 21 weeks old for genotyping, total IgY concentration analysis, and ND antibody titer analysis. SENSI-1 chickens were used as a comparison in the analysis of DMA gene polymorphism. The method for DNA polymorphism of DMA gene was direct-DNA sequencing. The total IgY concentration was analyzed using the indirect ELISA method, while the ND antibody titer used the HI test. Data were analyzed using GLM, genotypic, and haplotype mean values compared with t-test. The results showed that 4 SNPs were found, i.e., g.2328 G>A (exon 3), g.2503 A>G (intron 3), g.2612 G>A, and g.2686 G>A (exon 4). The SNPs of DMA gene were found polymorphic with three genotypes (GG, AG, and GG), and the expected SNP g.2503 A>G only had two genotypes (AA and GG). The g.2328 G>A was associated ( $<<0.05)$ with total IgY concentration. A combination of 4 SNPs formed 7 haplotypes. Haplotype 1 was associated with total IgY concentration $(\mathrm{p}<0.05)$, and haplotype 5 was associated with ND antibody titer $(\mathrm{p}<0.05)$. In conclusion, the $\mathrm{g} .2328$ G>A mutation and haplotype 1 could be potentially recommended as a genetic marker for high total IgY concentration, and haplotype 5 could be potentially recommended as a genetic marker for ND antibody titer in IPB-D2 chicken line.
\end{abstract}

Keywords: IPB-D2 line chickens; DMA gene; IgY concentration; ND antibody titers

\section{INTRODUCTION}

IPB-D1 chickens are a new breed of local Indonesian chickens (Ministry of Agriculture Reg No. 693/KPTS/PK.230/M/9/2019). IPB-D1 chicken results from crossbreeding between F1 male cross-breed of Pelung chicken and Sentul chicken (PS) with F1 female cross-breed Kampong chicken and Parent Stock Cobb. The superiority of this chicken is its fast growth, which reaches $1.178 \mathrm{~kg}$ (female) and 1.378 (male) slaughter weight at the age of 12 weeks (Al Habib et al., 2020). In addition, this chicken is also resistant to S. pullorum (Ulupi et al., 2016) and New Castle disease (Sumantri \& Darwati, 2017).

The formation of IPB-D2 chicken line is one of the efforts to increase the performance of local Indonesian chickens. IPB-D2 chickens were selected from IPB-D1 chickens according to disease resistance traits. The selection of IPB-D2 chickens is based on several immunocompetence parameters, i.e., total IgY concentration and ND antibody titer.
Immunoglobulin Yolk (IgY) is the major antibody in chicken. IgY accumulated in egg yolk provides a powerful immunity against avian pathogens to the chick (Wang et al., 2019). The IgY concentration indicates chicken's fitness, health, and nutritional state (Sun et al., 2013). Meanwhile, Newcastle disease (ND), a disease caused by the ND virus in the Paramyxoviridae family, occurs in many countries, including Indonesia (Indriani \& Dharmayanti, 2016). The mortality rate caused by ND is up to $80 \%$ (Dharmayanti et al., 2014). Antibodies neutralize ND virus particles by binding them and preventing the attachment of the virus to the host cells (Kapczynski et al., 2013). Studies related to disease resistance in IPB-D1 breed chickens have been reported before. Al Habib (2020) stated that the CD1B gene is associated with high IgY concentrations and high ND antibody titers.

The genetic interaction between the host and the pathogen is a crucial factor in disease resistance. The best and the most reliable approach to control infectious disease in chickens is by improving the genetic potential 
of disease-resistance genes. Genetic in different breeds may be explored to study the effect of disease resistance. Related genes to disease-resistance traits in chickens can be identified through QTL (mapping of the combination of DNA variations) and marker-assisted selection (MAS). Disease-resistance genes encode antibodies, microRNA, and other materials that help the host resist the damage caused by pathogens (Dar et al., 2018). In poultry, MHC genes have been associated with diseaseresistance traits (Jie \& Liu, 2011).

The DMA (DM $\alpha$ chain) gene is a non-classical MHC-class II gene member that plays an important role in generating antigen peptides by producing DM protein (Parker \& Kaufman, 2017). The DMA gene produces a DM-protein molecule that helps present exogenous antigens to $\mathrm{CD}^{+}$via MHC-class II molecules. The DMprotein molecule is encoded by $\alpha$-chain DM (DMA) and $\beta$-chain DM (DMB). Briefly, DM molecules accumulate endosomally and remove peptide chains that are incompatible with MHC-class II molecules, thus allowing MHC-class II molecules to bind to specific peptides and present them to the cell surface (Lian et al., 2010).

Benito et al. (2015) state that the adaptive immune response and the development of $\mathrm{CD} 4^{+}$cells require peptide exchange mediated by the DM molecule. Loading of internalized antigen is known to be DMdependent. The DMA gene is rich in genetic diversity related to immunity and disease resistance in chickens (LingLin et al., 2017). A study by Chazara et al. (2011) states that there are 4 SNPs in exon 3 of DMA gene, which form 9 variations of amino acids. The high variation in $\mathrm{MHC}$ is related to its role in the immune response, and several studies have shown positive selection at this locus. Studies related to the polymorphism and the association of MHC genes, especially DMA gene in IPB-D2 chickens, have never been reported. This study aims to identify the polymorphism of DMA gene and their associations with disease resistance traits, i.e., as total IgY concentration and ND antibody titer in IPB-D2 chickens. The results of this research are expected to produce potential markers to accelerate the selection and produce IPB-D2 chicken new line which has disease-resistance traits.

\section{MATERIALS AND METHODS}

\section{Animal Resource and Phenotypic Measurements}

The experimental procedure was approved by the Institutional Animal Care and Use Committee (IACUC) at IPB University (approval ID: 163-2019). The total sample used was 101 chickens consist of 81 IPB-D2 G0 chickens (53 female and 28 male) and 20 SENSI-1 chickens (15 female and 5 male). Blood samples were collected at 21 weeks old for genotyping, total IgY concentration analysis, and ND antibody titer analysis. SENSI-1 chickens were used as a comparison in the analysis of DMA gene polymorphism. IPB-D1 chickens were reared in an intensive system and chickens were raised until the age of 21 weeks. Chickens were kept in a cage with facilities for feeding, drinking water, laying eggs, and husks for the cage. The chicken was fed twice a day, in the morning and evening. The feed given was $100 \%$ commercial feed for DOC up to 4 weeks old and a mixture of commercial feed and rice bran with a ratio of 70:30 for 4 to 12 weeks old chickens. Chickens at 12 to 21 weeks old were given commercial feed and bran in a ratio of 60:40. Drinking water was given ad libitum.

The total IgY concentration was measured using the indirect ELISA method according to Khan et al. (2009). The microplates were coated with IgG goat anti-IgY (SAB3700195 Sigma-Aldrich) (with a concentration of $2.5 \mathrm{\mu gmL}^{-1}$ ) as a catching antibody, which was diluted with a bicarbonate buffer $\left(\mathrm{Na}_{2} \mathrm{NO}_{3}\right) \mathrm{pH} 9.6$ then incubated overnight at $4{ }^{\circ} \mathrm{C}$. The microplates were then washed three times using a phosphate-buffered saline solution and tween-20 (PBST-20, pH 7.4). Microplates were then blocked with $2 \%$ BSA $100 \mu \mathrm{L}$ per well, then incubated for 1 hour at $37{ }^{\circ} \mathrm{C}$. Furthermore, the microplates were washed again with PBST $0.05 \%$ three times. The $100 \mu \mathrm{L}$ serum samples were then inserted into each well with a 1:100 dilution, then incubated for 1 hour at $37^{\circ} \mathrm{C}$.

After being incubated and washed three times with PBST $0.05 \%, 100 \mu \mathrm{L}$ of secondary antibody IgG rabbit anti-IgY (A9046 Sigma-Aldrich) was inserted into each well conjugated with a peroxidase enzyme, then incubated at $37^{\circ} \mathrm{C}$ for 1 hour. The microplate was then washed with PBST three times, the last $100 \mu \mathrm{L}$ of the substrate was inserted into each well. Optical Density (OD) was read at a wavelength of $450 \mathrm{~nm}$ using a spectrophotometer.

The ND antibody titers were measured according to OIE (2012). The ND antibody titer test was carried out in two stages: the Haemagglutination test (HA test) and the Haemagglutination Inhibition test (HI test). The function of HA test is to identify the virus and calculate the viral titer that will be used. The HA test was carried out by filling all the $U$ bottom microplate wells with $25 \mu \mathrm{L}$ of PBS. Then as much as $25 \mu \mathrm{L}$ of the ND virus suspension was put into the first well and homogenized with a micropipette. A total of $25 \mu \mathrm{L}$ of the solution was taken, then transferred to the second well and homogenized with a micropipette, then $25 \mu \mathrm{L}$ was transferred to the third well, and so on until the $11^{\text {th }}$ well. In the $11^{\text {th }}$ well, $25 \mu \mathrm{L}$ was taken and discarded. Then $25 \mu \mathrm{L}$ of PBS was inserted into each well, followed by $25 \mu \mathrm{L}$ of $1 \%$ RBC. The microplate was then shaken and incubated at room temperature for approximately 30 minutes. The results are said to be positive when there is agglutination.

After the HA test was carried out, the HI test was carried out to determine the antibody titer held in the serum. HI test was carried out by filling all $U$ bottom microplate wells with $25 \mu \mathrm{L}$ of PBS. Then $25 \mu \mathrm{L}$ of serum was added to the first rinse, homogenized with a micropipette. A total of $25 \mu \mathrm{L}$ of the solution was taken from the first well, then transferred to the second well and homogenized with a micropipette. This stage was carried out until well 12 . In well $12,25 \mu \mathrm{L}$ was taken and discarded. The standard virus was put into all wells as much as $25 \mu \mathrm{L}$ and homogenized by shaking. Then the mixtures were incubated at room temperature for 30 minutes. After 30 minutes, $25 \mu \mathrm{L}$ of $1 \%$ RBC was added to each well. The microplate was shaken and then incubated for about 30 minutes, then the results were 
read. The HI test results were obtained after the hemagglutination inhibition reaction occurred in the positive control wells, and the final limit of the complete agglutination inhibition was the antibody titer produced.

\section{Polymorphism Analysis}

DNA extraction used the phenol-chloroform method based on Butler (2010). The target of DMA gene amplification was exon 3 and exon 4 (based on ENSGALG00000000158). Primers were designed using PrimerStat. The primers were as follows: 5'CATTCCCACCGATGTGTC-3 'for forwarding primer and 5' CTGCTGTCTCCATTGTCC-3 'for reverse primer. The PCR product was $601 \mathrm{bp}$. DNA amplification was carried out in a thermocycler machine (Applied Biosystem 9700). Cycles applied were predenaturation at $95{ }^{\circ} \mathrm{C}$ for 1 minute, denaturation at $95{ }^{\circ} \mathrm{C}$ for 15 seconds, annealing at $56{ }^{\circ} \mathrm{C}$ for 15 seconds, extension at $72{ }^{\circ} \mathrm{C}$ for 10 seconds, and final extension at $72{ }^{\circ} \mathrm{C}$ for 1 minute. PCR products were observed using UV Transilluminator (BioradTM, California, USA). DNA fragment results were then confirmed by direct DNA sequencing (1st Base in Selangor, Malaysia). The results of DMA gene sequencing were analyzed using MegaX, FinchTV, and Popgen32.

\section{Data Analysis}

Genetic polymorphism was analyzed by genotype and allele frequencies, Hardy-Weinberg Equilibrium, and Heterozygosity. The associations of DMA gene polymorphism with total IgY concentrations and ND antibody titer were analyzed using SAS 9.4 software (SAS Institute, Cary, NC, USA). The haplotype diversity was analyzed using DnaSP6. The statistical model used the General Linear Model (GLM), and the mean genotype and haplotype values were compared with the t-test. The statistical model for the GLM are:

$$
Y_{i j}=\mu+X_{i}+€_{i j}
$$

where $Y_{i j}$ was individual total IgY concentration and ND antibody titer, $\mu$ was overall means for total IgY concentration and ND antibody titer, $X_{i}$ was the genotype effect or haplotype, and $€_{\mathrm{ij}}$ was the random residual effect. A significant association was indicated by the P-value $(p<0.05)$. The number of haplotypes and linkage disequilibrium measures $\mathrm{D}^{\prime}$ and $\mathrm{R}^{2}$ were calculated with DnaSP (Ching et al., 2002).

\section{RESULTS}

\section{Polymorphism of DMA Gene}

The DMA gene in chickens is located on chromosome 16 with a length of $3410 \mathrm{bp}$ consisting of a promoter, 4 exons, and 3 introns. The PCR technique was used to amplify DNA segments the number of millions of times. DMA gene amplification used an annealing temperature of $56^{\circ} \mathrm{C}$ for 15 seconds with 35 repetitions cycles. The results of DMA gene amplification produced PCR products $601 \mathrm{bp}$ (Figure 1). A total of 4 SNPs were found, namely g.2328 G>A in exon 3, g.2503 A>G at intron 3, as well as g.2612 G>A and g.2686 G>A in exon 4 (Figure 2). All SNPs were classified as transition mutations. All SNP indicates a nonsynonymous or missense mutation that causes changes in amino acids g.2328 G>A valine>isoleucine, and g.2686 G>A arginine>glutamine except g.2612 G>A alanine>alanine (Figure 3, Table 1).

\section{Genotype, Allele Frequencies, and Heterozygosity}

There were 3 genotypes found at g.2328 G>A, g.2612 G>A, and g.2686 G>A, i.e., AA, AG, and GG. In contrast, at g.2503 $\mathrm{A}>\mathrm{G}$, there were only 2 genotypes found (AA and GG). Genotypes, allele frequencies, and heterozygosity are presented in Table 2 . The highest genotype frequency in IPB-D2 chickens was GG genotype at g.2328 G>A and g.2686 G>A. The highest genotype frequency at SNP g.2503 A>G and g.2612 G>A was the AA genotype for both IPB-D2 and SENSI-1 chickens. All SNPs were polymorphic except SNP g.2503 $A>G$ in SENSI-1 chickens. All SNPs were not in HardyWeinberg equilibrium. The Ho value was smaller than the He value on all SNPs.

\section{Haplotype Polymorphism of DMA Gene}

There were 7 haplotypes found in this study as a combination of 4 SNPs found, i.e., haplotype 1 to 7 (Table 3). Haplotype 2 is the same haplotype as the reference sequence with a haplotype frequency of $18.52 \%$. The highest haplotype was haplotype 1, with a haplotype frequency of $44.44 \%$. Haplotype 1 consisted of 3 SNP, i.e., g.2328 G>A, g.2612 G>A, and g.2686 G>A. The $\mathrm{D}$ values ranged from -1 to 1 (Jenna and Rosenberg 2008). The $R^{2}$ values varied from 0.18 to 0.64 .

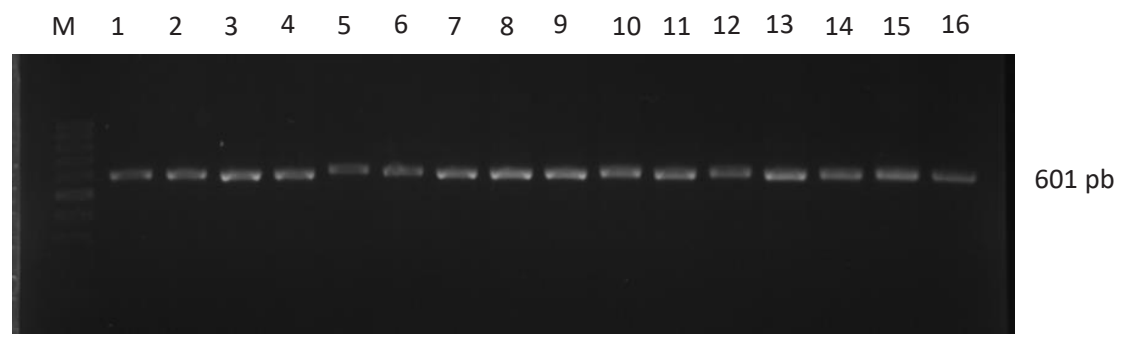

Figure 1. The amplification product of DMA gene fragment. $M=$ marker; 1-16= samples. The 100 bp DNA marker/ DNA ladder is designed for sizing and approximate quantification of double-stranded DNA in the range of $100 \mathrm{bp}$ to $2,000 \mathrm{bp}$. 
g. $2328 \mathrm{G}>\mathrm{A}$

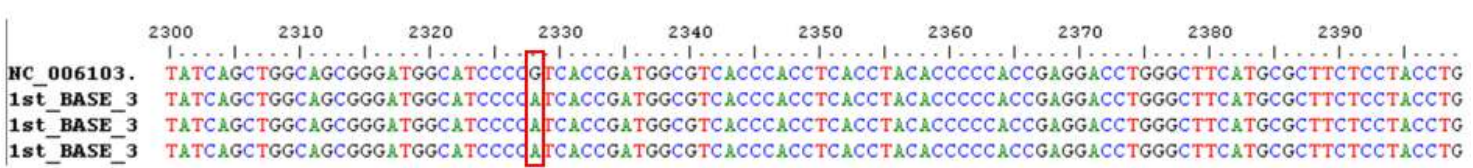

g. $2503 \mathrm{~A}>\mathrm{G}$

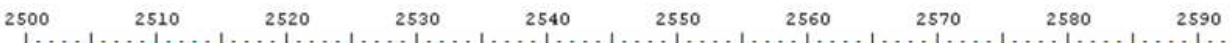

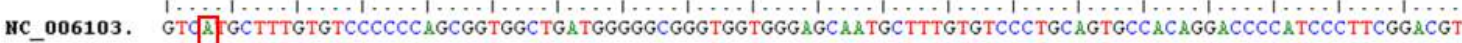
614.fasta GTdGFGCTTTGTGTCCCCGCAGCGGTGGCTGATGGGGGCGGGTGGTGGGAGCAATGCTTTGTGTCCCTGCAGTGCCACAGGACCCCATCCCTTCGGACGT 1st BASE 3 GTdGFGCTTTGTGCCCCGCAGCGGTGGCTGATGGGGGCGGGTGGTGGGAGCAATGCTTTGTGTCCCTGCAGTGCCACAGGACCCCATCCCTTCGGACGT $\begin{array}{ll}\text { 1st_BASE_3 } & \text { GTCGFGCTTTGTGTCCCCGCAGCGGTGGCTGATGGGGGCGGGTGGTGGGAGCAATGCTTTGTGTCCCTGCAGTGCCACAGGACCCCATCCCTTCGGACGT } \\ \text { 1st_BASE_4 } & \text { GTdGFGCTTTGTGTCCCCGCAGCGGTGGCTGATGGGGGCGGGTGGTGGGAGCAATGCTTTGTGTCCCTGCAGTGCCACAGGACCCCATCCCTTCGGACGT }\end{array}$

g. $2612 \mathrm{G}>\mathrm{A}$

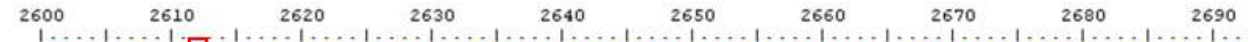

HC_006103. GTTGGCCACGGCGGTGTGCGGCGCAGTGACGGCGCTGGGCATCCTGCTGGCACTGCTGGGTTTGGGGCTGCTGCTGTCCGCCCGCCGGCGCAGTATGTGG 1st̂ BASE 3 GTTGGCCACGGD ATTGTGCGGCGCAGTGACGGCGCTGGGCATCCTGCTGGCACTGCTGGGTTTGGGGCTGCTGCTGTCCGCCCGCCAGCGCAGTATGTGG 1st-BASE-3 GTTGGCCACGG A GTGTGCGGCGCAGTGACGGCGCTGGGCATCCTGCTGGCACTGCTGGGTTTGGGGCTGCTGCTGTCCGCCCGCCAGCGCAGTATGTGG

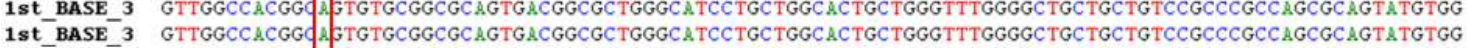

g. $2686 \mathrm{G}>\mathrm{A}$
2600
2610
2620
2630
2640
2650
2660
2670
2680
2690

HC 006103. GTTGGCCACGGCGGTGTGCGGCGCAGTGACGGCGCTGGGCATCCTGCTGGCACTGCTGGGTTTGGGGCTGCTGCTGTCCGCCCGCDGGCGCAGTATGTGG 1st BASE 3 GTTGGCC ICGGC \&GTGTGCGGCGC AGTGACGGCGCTGGGCATCCTGCTGGC \&CTGCTGGGTTTGGGGCTGCTGCTGTCCGCCCGC A ECGCAGT \&TGTGO 1st_BASE 3 GTTGGCCACGGCAGTGTGCGGCGCAGTGACGGCGCTGGGCATCCTGCTGGCACTGCTGGGTTTGGGGCTGCTGCTGTCCGCCCGCD A ECGCAGTATGTGO 1st_BASE_3 GTTGGCCACGGCAGTGTGCGGCGCAGTGACGGCGCTGGGCATCCTGCTGGCACTGCTGGGTTTGGGGTGCTGCTGTCCGCCCGCD

Figure 2. Identification of $\alpha$-chain DM (DMA) gene polymorphism, red box indicates each mutation.

\section{g. $2328 \mathrm{G}>\mathrm{A}$}

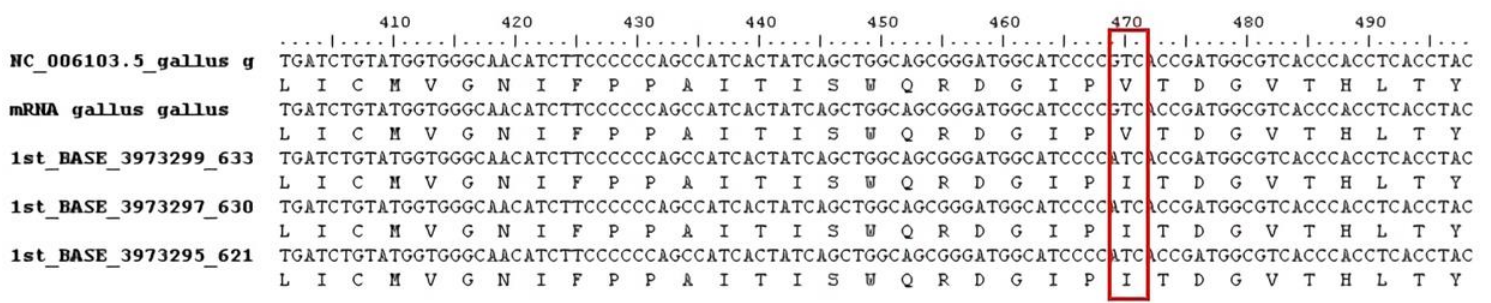

g. $2612 \mathrm{G}>\mathrm{A}$

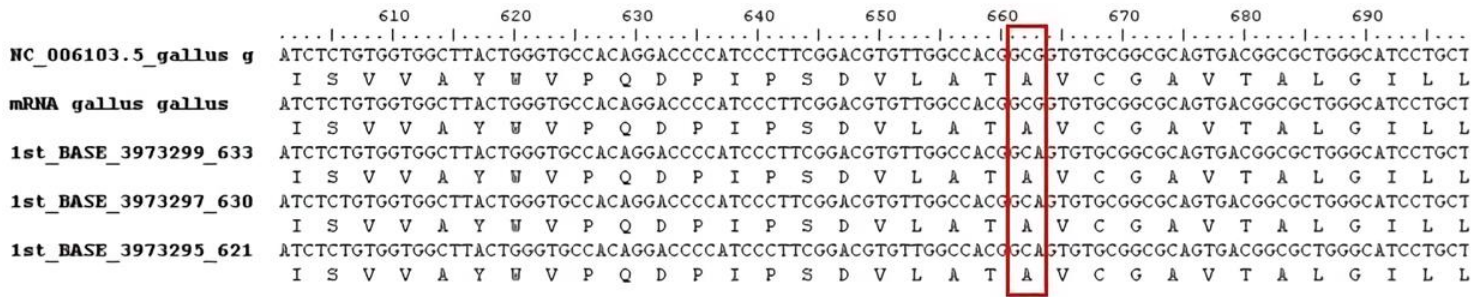

g. $26866 \mathrm{G}>\mathrm{A}$

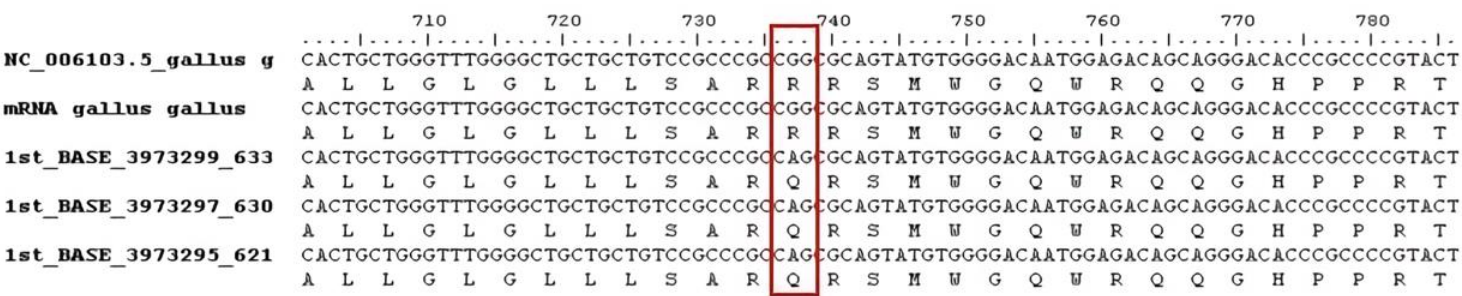

Figure 3. Amino acid changes, red box indicated amino acid changes. 
Table 1. Amino acid changes of $\alpha$-chain DM (DMA) gene in IPB-D2 chicken line

\begin{tabular}{|c|c|c|c|c|c|}
\hline No & SNP & Type of mutation & \multicolumn{3}{|c|}{ Amino acid } \\
\hline 1 & g.2328 G>A & Nonsynonymous & Valine & $>$ & Isoleucine \\
\hline 2 & g.2612 G>A & Synonymous & Alanine & $>$ & Alanine \\
\hline 3 & g.2686 G>A & Nonsynonymous & Arginine & $>$ & Glutamine \\
\hline
\end{tabular}

Table 2. Genotype frequency, allele frequency, heterozygosity, and Hardy-Weinberg equilibrium of $\alpha$-chain DM (DMA) gene polymorphism in IPB-D2 chicken line

\begin{tabular}{|c|c|c|c|c|c|c|c|c|}
\hline \multirow{2}{*}{ SNP/Population } & \multicolumn{3}{|c|}{ Genotype frequency } & \multicolumn{2}{|c|}{ Allele frequency } & \multirow{2}{*}{$x^{2}$} & \multirow{2}{*}{ Ho } & \multirow{2}{*}{$\mathrm{He}$} \\
\hline & GG & AG & $\mathrm{AA}$ & G & A & & & \\
\hline \multicolumn{9}{|l|}{ g.2328 G>A } \\
\hline IPB-D2 (81) & 0.48 & 0.07 & 0.44 & 0.51 & 0.49 & $0.000^{\mathrm{s}}$ & 0.07 & 0.50 \\
\hline SENSI-1 (20) & 0.40 & 0.10 & 0.5 & 0.45 & 0.55 & $0.000^{\mathrm{s}}$ & 0.10 & 0.50 \\
\hline \multicolumn{9}{|l|}{ g. $2503 A>G$} \\
\hline IPB-D2 (81) & 0.13 & 0 & 0.86 & 0.13 & 0.87 & $0.000^{\mathrm{s}}$ & 0 & 0.23 \\
\hline SENSI-1 (20) & 0 & 0 & 0 & 0 & 1 & & 0 & 0 \\
\hline \multicolumn{9}{|l|}{ g.2612 G>A } \\
\hline IPB-D2 (81) & 0.38 & 0.12 & 0.49 & 0.44 & 0.56 & $0.000^{\mathrm{s}}$ & 0.12 & 0.49 \\
\hline SENSI-1 (20) & 0.40 & 0.10 & 0.50 & 0.45 & 0.55 & $0.000^{\mathrm{s}}$ & 0.10 & 0.50 \\
\hline \multicolumn{9}{|l|}{ g.2686 G>A } \\
\hline IPB-D2 (81) & 0.48 & 0.09 & 0.41 & 0.53 & 0.47 & $0.000^{\mathrm{s}}$ & 0.09 & 0.50 \\
\hline SENSI-1 (20) & 0.40 & 0.10 & 0.50 & 0.45 & 0.55 & $0.000^{\mathrm{s}}$ & 0.10 & 0.50 \\
\hline
\end{tabular}

Note: $\mathrm{Ho}=$ observed heterozygosity; $\mathrm{He}=$ expected heterozygosity; $\mathrm{s}=$ significant $(\mathrm{p}<0.05)$.

Table 3. Haplotype polymorphism of $\alpha$-chain DM (DMA) gene in IPB-D2 chicken line

\begin{tabular}{|c|c|c|c|c|c|}
\hline \multirow{2}{*}{ Haplotype } & \multicolumn{4}{|c|}{ SNPs } & \multirow{2}{*}{ Frequency (\%) } \\
\hline & g.2328 G>A & g.2503 $A>G$ & g.2612 G>A & g.2686 G>A & \\
\hline Haplotype 1 & $\mathrm{~A}$ & A & $\mathrm{A}$ & A & 44.44 \\
\hline Haplotype 2 & G & A & G & G & 18.52 \\
\hline Haplotype 3 & G & G & G & G & 16.05 \\
\hline Haplotype 4 & G & A & A & G & 11.11 \\
\hline Haplotype 5 & A & G & A & G & 4.94 \\
\hline Haplotype 6 & G & A & G & A & 3.70 \\
\hline Haplotype 7 & G & A & A & A & 1.23 \\
\hline Total & & & & & 100 \\
\hline
\end{tabular}

\section{Association of Genotypes and Haplotypes with Total IgY Concentration and ND Antibody Titer}

The genotype with the highest total IgY concentration of each SNP was the AA genotype. The association of genotypes with total IgY concentration and ND antibody titer is presented in Table 4. The g.2328 G>A was associated with the total concentration of IgY in IPB-D2 chicken. The AA genotype was significantly different from the AG genotype in IPB-D2 chickens $(p<0.05)$. The AG genotype had the highest average ND antibody titer value compared to the AA and GG genotypes.

Haplotype 1 had the highest total IgY concentration among all haplotypes and was significantly different $(\mathrm{p}<0.05)$ from haplotype 4 and haplotype 6. Haplotype 5 had the highest ND antibody titer among all haplotypes and was significantly different $(\mathrm{p}<0.05)$ from haplotype 2, but not significantly different from haplotypes 1, 3, and 4 . Associations between haplotype polymorphism with total IgY concentration and ND antibody titer were presented in Table 5.

\section{DISCUSSION}

\section{Polymorphism, Genotype, Allele Frequencies, and Heterozygosity of DMA Gene}

The Major Histocompatibility Complex (MHC) is a gene region found in all types of vertebrates that controls immune response (Miller \& Taylor, 2016). MHC in chickens is located on chromosome 16. MHC is divided into three classes, namely class I (BF), class II (BL), and class IV (BG) (Tizard, 2013). MHC class II consists of $\alpha$ chains and $\beta$ chains expressed only by APC (Antigen Presenting Cell). MHC class II molecules present exogenous molecules derived from exogenous antigens (Chazara et al., 2011). The MHC class II molecule carrying the peptide then presents the peptide to the cell surface. T cells display $\mathrm{CD}^{+}$only with $\mathrm{MHC}$ class II molecules (Glodsby et al., 2000).

The DMA gene produces a DM protein molecule that helps present exogenous antigens to $\mathrm{CD}^{+}$via $\mathrm{MHC}$ class II molecules. DM molecules accumulate endo- 
Table 4. Association between $\alpha$-chain DM (DMA) gene polymorphism with total IgY concentration and Newcastle disease (ND) antibody titer in IPB-D2 chicken line

\begin{tabular}{|c|c|c|c|}
\hline \multirow{2}{*}{ SNP } & \multirow{2}{*}{ Genotipe } & \multicolumn{2}{|c|}{ Disease resistance traits } \\
\hline & & $\operatorname{IgY} \mathrm{mg} \mathrm{mL}^{-1}(\mathrm{n})$ & ND antibody titer $\log 2 \mathrm{HI}$ Unit (n) \\
\hline \multirow{3}{*}{ g. $2328 \mathrm{G}>\mathrm{A}$} & GG & $9.33 \pm 2.41^{\mathrm{ab}}(39)$ & $3.00 \pm 2.21(23)$ \\
\hline & AG & $8.59 \pm 2.09^{\mathrm{b}}(6)$ & $4.00 \pm 1.73(4)$ \\
\hline & AA & $10.28 \pm 1.77^{a}(36)$ & $3.00 \pm 2.21(24)$ \\
\hline \multirow{3}{*}{ g. $2503 \mathrm{~A}>\mathrm{G}$} & GG & $9.04 \pm 2.65(11)$ & $4.55 \pm 2.35(9)$ \\
\hline & AG & & \\
\hline & AA & $9.48 \pm 2.29(70)$ & $3.32 \pm 2.74(46)$ \\
\hline \multirow{3}{*}{ g.2612 G>A } & GG & $9.48 \pm 2.51(31)$ & $3.15 \pm 2.90(20)$ \\
\hline & AG & $8.90 \pm 2.23(10)$ & $4.00 \pm 1.15(7)$ \\
\hline & AA & $10.06 \pm 1.82(40)$ & $3.70 \pm 2.97(24)$ \\
\hline \multirow{3}{*}{ g.2686 G>A } & GG & $9.26 \pm 2.38(39)$ & $3.23 \pm 2.89(21)$ \\
\hline & AG & $9.44 \pm 2.12(8)$ & $6.50 \pm 2.12(2)$ \\
\hline & AA & $10.27 \pm 1.83(34)$ & $3.42 \pm 2.4828)$ \\
\hline
\end{tabular}

Note: Means in the same column with different superscripts differ significantly between genotypes $(\mathrm{p}<0.05)$.

Table 5. Haplotype association with total IgY concentration and Newcastle disease (ND) antibody titer in IPB-2 chicken line

\begin{tabular}{ccc}
\hline Haplotype & $\operatorname{IgY~mg~mL} L^{-1}(\mathrm{n})$ & $\begin{array}{c}\text { ND antibody titer } \\
\log 2 \mathrm{HI} \text { Unit }(\mathrm{n})\end{array}$ \\
\hline Haplotype 1 & $10.50 \pm 1.80^{\mathrm{a}}(36)$ & $4 \pm 2.99^{\mathrm{ab}}(22)$ \\
Haplotype 2 & $9.61 \pm 2.50^{\mathrm{ab}}(16)$ & $1.81 \pm 2.27^{\mathrm{b}}(11)$ \\
Haplotype 3 & $8.98 \pm 2.51^{\mathrm{ab}}(13)$ & $4.22 \pm 2.77^{\mathrm{ab}}(9)$ \\
Haplotype 4 & $8.21 \pm 1.77^{\mathrm{b}}(8)$ & $3.60 \pm 0.89^{\mathrm{ab}}(5)$ \\
Haplotype 5 & $9.54 \pm 2.16^{\mathrm{ab}}(4)$ & $5.00 \pm 2.44^{\mathrm{a}}(4)$ \\
Haplotype 6 & $7.93 \pm 0.86^{\mathrm{b}}(3)$ & $1.00 \pm 0.00(1)$ \\
Haplotype 7 & $9.64 \pm 0.0(1)$ & 0 \\
\hline
\end{tabular}

Note: Means in the same column with different superscripts differ significantly between haplotypes $(\mathrm{p}<0.05)$.

somally and remove peptide chains that are incompatible with MHC class II molecules, thus allowing MHC class II to bind to specific peptides and present them to the cell surface (Lian et al., 2010). MHC in chickens is associated with the immune response to antigen synthesis, serum albumin, total IgY levels, and cell-to-cell response. Genes in MHC class II control the interaction of T cells, B cells, and macrophage cells in humoral immune response and cellular immunity (Bharathi et al., 2016).

Based on the results of the analysis of DMA gene polymorphism, 4 SNPs were found; namely g.2328 G>A in exon 3, g.2503 A>G in intron 3, and g.2612 G>A and g.2686 G>A in exon 4. The highest genotype frequency was AA at g.2503 A>G and g.2612 G>A in IPB-D2 and SENSI-1 chickens. Genotype frequency is the number of individuals with a particular genotype in a population divided by the total number in that population (Eybpoosh, 2018). The highest allele frequency at SNP g.2328 G>A and g.2686 G>A in IPB-D2 chickens was the $\mathrm{G}$ allele around 50\%. Whereas at SNP g.2503 A>G and g.2612 G>A, the A allele was about $86 \%$ and $55 \%$, respectively. Allele frequency is the proportion of a variant of a gene (allele) in a given locus among all alleles in the population. Based on the allele frequency of all
SNP in IPB-D2 are polymorphic. SNP is categorized as polymorphic if the allele frequency is $\leq 0.99$ in a large population and $\leq 0.95$ in a small population (Allendorf \& Luikart, 2007). Both allele and genotype frequencies are proportion in nature, meaning they can hold a range between 0 and 1 .

All SNPs have lower Ho than $\mathrm{He}$ indicating that inbreeding has occurred in IPB-D2 and SENSI-1 chicken populations. If the observed heterozygosity is lower than expected, it indicates the existence of inbreeding (Zhao et al., 2019). High heterozygosity means lots of genetic variabilities, and low heterozygosity means little genetic variability. As well as the chi-square test (x2) that indicates Hardy-Weinberg equilibrium, all SNPs were not in Hardy-Weinberg equilibrium that indicates inbreeding has occurred in IPB-D2 chicken SENSI-1 chicken population. A population is in Hardy-Weinberg equilibrium if there is no mutation, random mating, large population size, and natural selection (Eybpoosh, 2018).

Based on the result (Table 1), all SNPs are classified as transition mutations. Transition is substitution between $A$ and $G$ (purines) or between $C$ dan $T$ (pyrimidines) (Graur, 2003). A mutation is a change in the nucleotide sequence in coding portions of the DNA which may alter the amino acid sequences of proteins or a change in non-coding regions of DNA which has the potential for changing expression of the gene, for example, by altering the strength of a promoter (Mahdieh \& Rabbani, 2013). It causes changes in the amino acids valine $>$ isoleucine, arginine $>$ glutamine. Mutations that cause changes in amino acids are called non-synonymous or missense mutations (Hamilton, 2009).

\section{Association of Genotypes and Haplotypes with Total IgY Concentration and ND Antibody Titer}

The total concentration of IgY in IPB-D2 chickens was between $8-10 \mathrm{mg} \mathrm{mL}^{-1}$. There are three types of immunoglobulins in chickens, namely $\operatorname{IgM}, \operatorname{IgA}$, and IgY. IgY or yolk immunoglobulin is the main antibody in chickens. IgY accumulates in egg yolks and is used as 
Table 6. Linkage values estimated in the disequilibrium analysis among four SNPs identified in the $\alpha$-chain DM (DMA) gene in IPB-D2 chicken line

\begin{tabular}{ccccccc}
\hline SNPa & SNP 1/2 & SNP 1/3 & SNP 1/4 & SNP 2/3 & SNP 2/4 & SNP 3/4 \\
\hline $\mathrm{D}^{\prime}$ & -1.00 & -1.00 & 0.80 & 1.00 & -1.00 & -0.80 \\
$\mathrm{R}^{2}$ & 0.18 & 0.60 & 0.64 & 0.30 & 0.18 & 0.39 \\
\hline
\end{tabular}

Note: $\mathrm{SNPa}=$ estimated LD values $\left(\mathrm{D}^{\prime}\right.$ and $\mathrm{R}^{2}$ ) between polymorphism pairs; SNP 1= g.2328 G>A; SNP 2= g.2503 A>G; SNP 3= g.2612 G>A; SNP 4= g.2686 $\mathrm{G}>\mathrm{A}$.

the main antibody in chicks against pathogens (Wang, 2019). According to Oberlander et al. (2020), the concentration of each immunoglobulin are $\mathrm{IgY} 5-10 \mathrm{mg} \mathrm{mL}^{-1}$, IgM 1-2 mg mL-1 ${ }^{1}$, and IgA around 3 mg mL-1.

Genotype AA at g.2328 G>A was significantly different $(p<0.05)$ from the AG genotype. The AA genotype on each SNP had a higher mean IgY concentration compared to the other genotypes. The AA genotype on each SNP can be used as an indicator of high IgY concentrations.

The antibody titer of chicken IPB-D2 was in the moderate to protective category. According to Rahman et al. (2017), antibody titer level for ND $3 \log 2 \mathrm{HI}$ unit is categorized as a moderate protective level while $\geq 4 \log$ $2 \mathrm{HI}$ unit is categorized as a protective level for chickens that are vaccinated. Antibodies neutralize ND virus particles by binding and preventing attachment of the virus to host cells (Kapczynski et al., 2013). Cell-mediated immunity (CMI) is a specific adaptive immunity mediated by T lymphocytes and has been suggested to be an important factor in developing protection in chickens vaccinated against NDV. CMI derived from inactivated vaccines appear to be stimulated through $\mathrm{CD} 4^{+}$lymphocytes and MHC class II presentation that drive antibody formation likely through directed cytokine secretion (Kapczynski et al., 2013). The AG genotype has an average ND antibody titer value higher than the other genotypes at SNP g.2328 G>A, g.2612 G>A, and g.2686 $\mathrm{G}>\mathrm{A}$ in IPB-D2 chickens with ND antibody titers above $4 \log 2$ HI unit. The association of DMA gene diversity with ND antibody titers showed that all SNPs in IPB-D2 chickens were not associated with ND antibody titers $(\mathrm{p}>0.05)$.

All SNPs 4 SNPs combined into 7 haplotypes. The haplotype is the combination of alleles at loci found on a single chromosome or DNA molecule (Allendorf \& Luikart, 2007). The number of haplotypes formed in a locus depends on the number of SNPs, frequency, and their recombination rate (Stumpf, 2004). In this study, haplotype 2 is a wild type. Haplotype 1 was the haplotype with the highest total IgY concentration. Nucleotide changes in exon 3 (g.2328 G>A) and exon 4 (g.2612 G>A and g.2686 G>A) of the DMA gene predicted caused haplotype 1 to have the highest total IgY concentration.

Linkage disequilibrium (LD) is the non-random association of alleles at two or more loci. LD is used to determine the evolutionary forces that contribute to the genetic variation in a population. There are two commonly used measures of LD. The $\mathrm{D}^{\prime}$ measure is a standardized LD value that is dependent on allele frequencies. The $\mathrm{R}^{2}$ is defined as the square correlation co-efficient between two loci (Khanyile et al., 2015). The estimated values of LD analysis among four SNP are shown in Table 6. The $\mathrm{D}^{\prime}$ values varied from -1.00 to 1.00 . The $\mathrm{D}^{\prime}$ values ranged from -1 to 1 (Jenna \& Rosenberg, 2008). The $\mathrm{R}^{2}$ values varied from 0.18 to 0.64 . The $\mathrm{D}^{\prime}$ value between SNP 2 and 3 was 1.00 with a small $R^{2} 0.3$. Further studies such as DMA gene expression and 3D protein structure analysis are needed to strengthen these findings.

\section{CONCLUSION}

The DMA gene was polymorphic in IPB-D2 chickens. Four SNPs of DMA gene in IPB-D2 were found, i.e., g.2328 G>A, g.2503 A>G, g.2612 G>A, and g.2686 G>A. SNP g.2328 G>A was associated with total IgY concentration. A combination of four SNP formed 7 haplotypes. The present finding showed that haplotype 1 could be used as a parameter in the selection program of high total IgY concentration and haplotype 5 for high ND antibody titers.

\section{CONFLICT OF INTEREST}

Cece Sumantri serves as an editor of the Tropical Animal Science Journal, but has no role in the decision to publish this article. The authors have no conflict of interest with any personal, financial, or other relationship with people or other organizations regarding the material discussed in the manuscript.

\section{ACKNOWLEDGEMENT}

This research was supported by the Directorate of Research and Community Services, Deputy for Strengthening Research and Development, Ministry of Research, Technology/ National Research and Innovation Agency of The Republic of Indonesia in the PMDSU Program (Contract No. 077/SP2H/LT/ DRPM/2021).

\section{REFERENCES}

Al-Habib, M. F., S. Murtini, A. Gunawan, N. Ulupi, \& C. Sumantri. 2020. Polymorphism of CD1B gene and its association with yolk immunoglobulin (IgY) concentration and Newcastle disease antibody titer in IPB-D1 chicken. Trop. Anim. Sci. J. 43:197-204. https://doi.org/10.5398/ tasj.2020.43.3.197

Al-Habib, M. F., S. Murtini, L. Cyrilla, I. I. Arief, R. Mutia, \& C. Sumatri. 2020. Performa pertumbuhan ayam IPB-D1 pada perlakuan pakan dan manajemen pemeliharaan yang berbeda. J. Agripet. 20:177-186. https://doi.org/10.17969/ agripet.v20i2.16375

Allendorf, F. W. \& G. H. Luikart. 2007. Conservation and The Genetics of Populations. Blackwell Publishing, Oxford. 
Benito, M. A., M. Wieczorek, J. Sticht, C. Kipar, \& C. Freund. 2015. HLA-DMA polymorphisms differentially affect MHC class II peptide loading. J. Immunol. 194:803-816. https://doi.org/10.4049/jimmunol.1401389

Bharathi, I., R. Manohar, \& P. Shamsudeen. 2016. Selection methods for disease resistance in poultry - An Overview. Int. J. Sci. Environ. Technol. 5:810-815.

Butler, J. M. 2010. Fundamentals of Forensic DNA Typing. Elsevier, California.

Chazara, O., M. Tixier-Boichard, V. Morin, R. Zoorob, \& B. Bed'Hom. 2011. Organization and diversity of the class II DM region of the chicken MHC. Mol. Immunol. 48:12631271. https://doi.org/10.1016/j.molimm.2011.03.009

Ching, A. K. S. Caldwell, M. Jung, M. Dolan, O. S. Smith, S. Tingey, M. Morgante, \& A. J. Rafalski. 2002. SNP frequency, haplotype structure and linkage disequilibrium in elite maize inbred lines. BMC Genet. 3:1-14. https://doi. org/10.1186/1471-2156-3-19

Dar, M. A., P. T. Mumtaz, S. A. Bhat, M. Nabi, Q. Taban, R. A. Shah, H. M. Khan, \& S. M. Ahmad. 2018. Genetics of Disease Resistance in Chicken. In: X. Liu (Eds). Application of Genetics and Genomics in Poultry Science. Chapter 61277. IntechOpen, London. https://doi.org/10.5772/ intechopen.77088

Dharmayanti, N. L. P. I., R. Hartawan, D. A. Hewajuli, \& R. Inriani. 2014. Phylogenetic analysis of genotype VII of new castle disease virus in Indonesia. Afr. J. Microbiol. Res. 8:1368-1374. https://doi.org/10.5897/AJMR2014.6601

Eybpoosh, S. 2018. Hardy Weinberg equilibrium testing and interpretation focus on infection. J. Med. Microbiol. Infect. Dis. 6:35-36. https://doi.org/10.29252/JoMMID.6.1.35

Goldsby, R. A., T. J. Kindt, \& B. A. Osbourne. 2000. Kuby Immunology. WH Freeman, New York.

Graur, D. 2003. Nature Encyclopedia of The Human Genome. Macmillan Publishers Ltd, New York.

Hamilton, M. B. 2009. Population Genetics. John Wiley \& Sons, UK.

Indriani, R. \& I. Dharmayanti. 2016. Respon titer antibodi dan proteksi virus Newcastle Disease genotype I, II, VI dan VII sebagai vaksin terhadap infeksi isolate virus Newcastle Disease chicken/Indonesia/GTT/11. Jurnal Biologi Indonesia 12:211-218. https://doi.org/10.14203/jbi. v12i2.2887

Jie, H. \& Y. P. Liu. 2011. Breeding for disease resistance in poultry: Opportunities with challenges. Worlds Poult. Sci. J. 67:687-696. https://doi.org/10.1017/S0043933911000766

Kapczynski, D. R., C. L. Afonso, \& P. J. Miller. 2013. Immune responses of poultry to Newcastle disease virus. Dev. Comp. Immunol. 1-7.

Khan, M., S. Jahan, M. C. Paul, D. Chakraborty, \& M. R. Islam. 2009. Development of an Indirect ELISA technique towards detection of antibodies to Infectious Bursal Disease Virus (IBDV) of chickens. Bangladesh Vet. J. 43:8-16.

Khanyile, K. S., E. F. Dzomba, \& F. C. Muchadeyi. 2015. Linkage disequilibrium in the estimation of genetic and demographic parameters of extensively raised chicken population. Worlds Poult. Sci. J. 71:505-514. https://doi. org/10.1017/S0043933915002202

Lian, L., L. J. Qu, J. X. Zheng, C. J. Liu, Y. P. Zhang, Y. M. Cheng, G. Y. Xu, \& N. Yang. 2010. Expression profiles of genes within a subregion of chicken major histocompability complex B in spleen after Marek's disease virus infection. Poult. Sci. 89:2123-2129. https://doi.org/10.3382/ ps.2010-00919

Linglin, K., Z. Shenghan, C. Ying, Z. Pengfei, W. Yun, G. Qixin, C. Guohong, \& C. Guboin. 2017. Comparative analysis of DMA gene sequences in different chicken breeds. Acta Agriculturae Zhejiangensis 29:60-565. https:// doi.org/10.3969/j.issn.1004-1524.2017.04.07

Mahdieh, N. \& B. Rabbani. 2013. An overview of mutation detection methods in genetic disorders. Iran J. Pediatr. 23:375-388.

Miller, M. M. \& R. L. Taylor. 2016. Brief review of the chicken Major Histocompatibility Complex: the genes, their distribution on chromosome 16, and their contribution to disease resistance. Poult. Sci. 95:375-392. https://doi. org $/ 10.3382 / \mathrm{ps} /$ pev379

Oberlander, B., K. Failing, C. M. Jungst, N. Neuhaus, M. Kierz, \& F. M. Paula-Ribes. 2020. Evaluation of Newcastle Disease antibody titers in backyard poultry in Germany with a vaccination interval of twelve weeks. PLoS ONE 15:1-14. https://doi.org/10.1371/journal.pone.0238068

Parker, A. \& J. Kaufman. 2017. What chickens might tell us about the MHC class II system. Immunology 46:23-29. https://doi.org/10.1016/j.coi.2017.03.013

Rahman, M. Mostafijur, Sarker, R. Deb, \& M. Nooruzzaman. 2017. Evaluation of serum antibody titer level against Newcastle disease virus in vaccinated broiler chickens. AVAS 4:94-98.

Stumpf, M. P. H. 2004. Haplotype diversity and SNP frequency dependence in the description of genetic variation. Eur. J. Hum. Genet. 12:469-477. https://doi.org/10.1038/ sj.ejhg.5201179

Tizard, I. R. 2013. Veterinary Immunology. Elsevier Saunder, China.

Ulupi, N., C. Sumantri, \& S. Darwati. 2016. Resistance against Salmonella pullorum in IPB-D1 crossbreed, kampong and commercial broiler chicken. The 1st Conference Technology on Bioscience and Social Science 2016. Universitas Andalas, Padang.

Wang, Q., F. Wang, L. Liu, Q. Lie, R. Liu, M. Zheng, H. Cui, J. Wen, \& G. Zhao. 2019. Genetic mutation analysis of high and low IgY chickens by capture sequencing. Animals 9:110. https://doi.org/10.3390/ani9050272

Zhao, Q., H. Sun, Z. Zhang, Z. Xu, B. S. Olesege, P. Ma, Z. Zhang, Q. Wang, \& Y. Pan. 2019. Exploring the structure of haplotype blocks and genetic diversity in Chinese Indigenous pig populations for conservation purpose. Evol. Bioinform. 15:1-8. https://doi.org/10.1177/1176934318825082 